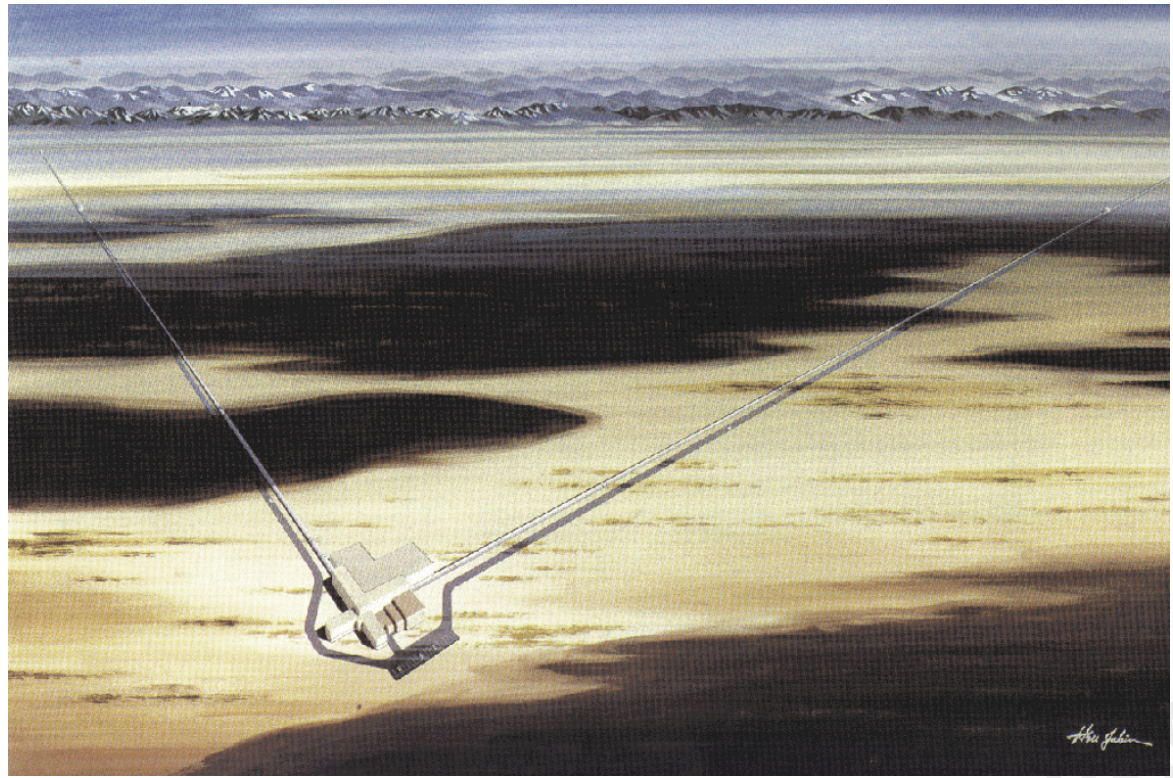

Ripple detector: artist's impression of the Laser Interferometer Gravitational-Wave Observatory, taken from the LIGO website (http://www.ligo.caltech.edu).

bars separated by thousands of miles 'rang' in coincidence, Weber argued that gravitational waves were a putative cause of the disturbance; the source could be cosmic catastrophes such as supernovae.

By the early 1970s, Weber's claims had become so forceful that others built similar devices, but by the mid-1970s most people thought Weber was mistaken. Blair and George McNamara provide a colourful description of a confrontation between Weber and Richard Garwin at a conference in the 1970s that might have come to blows had the chairman not stepped in. Weber continues to press his claims, but most of the rest of the field moved on long ago.

The next generation of detectors were Weber bars cooled to liquid-helium temperatures and below. Blair himself runs such a device, although his bar is niobium rather than aluminium. Such attempts to detect gravitational waves are dealt with in the last third of the book. The first section is a short history of science, taking us through Newton to general relativity and the curvature of space, and in the middle is a section about potential sources of gravitational waves. The 'nuclear submarine problem' makes it impossible to generate detectable fluxes on Earth, so we must look to cosmic sources. The huge curvatures and energies associated with cavorting neutron stars and black holes make them the current favourites.

Astronomers Joseph Taylor and Russell Hulse studied the decay of a pair of orbiting pulsars over 20 years. The slowdown of 70 microseconds per year in an orbit of sevenand-three-quarter hours fits well with the predicted loss of energy through gravitational radiation. The 1993 Nobel prize for physics was awarded to Taylor and Hulse for this first indirect confirmation of the existence of the waves, but direct observation is still the holy grail.

Towards the end of their orbital decay (in about 300 million years for the Taylor-Hulse pair), neutron stars nearly touch and circle hundreds of times per second. The final inspiral should produce a characteristic 'chirrup' of gravitational radiation of enormous power, about as bright as 100,000 galaxies. But even these immense fluxes will bend space so little that they will be on the edge of detectability by the most advanced interferometers now being designed. Colliding black holes should be even more fun, and there ought also to be a just-detectable background of gravitational radiation left over from the Big Bang.

Ripples on a Cosmic Sea is currently without competitors. However, parts of the book are so relentlessly 'popular' as to be patronizing. The most informative chapters are those dealing with pulsar sources, and those describing detectors and their inventors. Chapter 12, on laser interferometry, is especially good. It presents important ideas clearly, not shirking complicated new techniques. It also mentions the more operatic organizational upheavals that have attended the US programme and the dirty dealings associated with the funding of different national projects. These chapters provide a nice account of sources and technology and a good thumbnail sketch of the field's history. The book could then be passed on to a young niece or nephew.

Those who get a taste for the science of gravitational radiation detection from the book might want to borrow a library copy of Peter Saulson's Principles of Interferometric Gravitational Radiation Detectors, which includes a short section on resonant bars, or Blair's edited collection of technical essays The Detection of Gravitational Waves. In both books the equations are supplemented with good clear writing, but you'll need to be rich to buy them.

Harry Collins is at the Centre for the Study of Knowledge, Expertise and Science, University of Wales at Cardiff, 50 Park Place, CardiffCF1 3AT, UK.

e-mail:collinshm@cardiff.ac.uk

\section{Disregarding the social sciences}

\section{Is the Temperature Rising? The Uncertain Science of Global Warming}

by S. George Philander

Princeton University Press: 1998. Pp. 258.

$\$ 35, £ 22.50$

\section{Hans von Storch}

'Global warming' has become a household term; it needs no explanation when used in the news. 'Is the temperature rising?' is a question of utmost interest to anyone concerned about the global environment. Both phrases announce the subject of this book.

The volume is based on a course for undergraduate students given by the author at Princeton University, so it is also well suited to educated laypeople. It is written clearly and contains informative figures. The extensive appendices provide additional technical material, and an eight-page glossary is included.

The author explains complex scientific concepts in a precise language and with delightful illustrations. Of the waves on the ocean's surface, he writes: "A breeze that blows over the ocean, like a bow that strokes a violin string, readily excites music in the form of waves. The audible sound of a violin is soothing when the pressure from the bow is gentle and becomes strident when the pressure is great. The ocean's music changes similarly from ripples ... to foaming, lashing waves as the gentle breeze grows stiff ... and becomes a gale that whips the ocean into frenzy." He describes the weather as the "music of our sphere" and explains the principle of chaos using a thought-experiment of a skier losing his or her wallet on a slope. The book is a pleasure to read.

But its title is deceptive. Most of the volume explains the workings of the climate machinery and its components such as radiation, clouds, weather and oceans. The question 'Is the temperature rising?' is dealt with only on two pages in the last chapter.

The answer is 'yes', which will be no surprise to anybody who knows the observational record compiled by the University of East Anglia in England. The more interesting question 'Will the temperature continue to rise?' is dealt with in even fewer lines: the author quotes "very probable" rates of increase of $0.5-2{ }^{\circ} \mathrm{C}$ until about 2050 , from 
studies of climate models forced with continually increasing greenhouse gas concentrations.

The author reduces the uncertainty of climate science mostly to the fundamental problem of nonlinear dynamics and the related problem of determining accurate initial conditions. Other fundamental aspects are neglected, such as the climate system's phase space with infinitely many degrees of freedom, the openness of the system and the need to impose various semi-empirical parameters on climate models. As a result, the book comes across as over-optimistic about the task of analysing and modelling the climate system and its sensitivity.

As to the science of global warming, the author takes this to mean the purely physical sciences, exploring myriad processes that take place in the atmosphere, the oceans, the lithosphere and so on. Thus a planetaryscale view of global warming emerges, with relocated deserts, rising sea level, a defunct Gulf Stream and more El Niño events. What these changes mean for humankind is not specified. Instead, the author stays vague, mentioning the "considerable inconvenience over the next few decades for our particular species" and issuing general warnings about forthcoming unspecified "dangers".

The science of global warming should, however, also deal with the specifics of these dangers: that is, it should look at the possibility of abating and adapting to them. And as ecosystems and people experience global warming mostly locally, this analysis must be done on the local scale.

The author mentions Thomas Malthus's prediction, 200 years ago, that England was heading towards "gigantic inevitable famine" because of the steady increase in population. Perhaps we should learn from Malthus's science that the fate of the environment and humankind is only partly determined by natural dynamics, such as population growth and the carbon cycle, and that social dynamics and technological innovations are important as well.

Every scenario of possible future climate change is based on scenarios about the anthropogenic output of greenhouse gases: that is, on the outcome of a highly complex social system. The challenge of climate science therefore is to integrate the social sciences - by coupling economics models, diagnosing the socio-scientific construction of the 'climate problem' or analysing the impact of climate policy on people's wellbeing. Unfortunately, the author has chosen not to take up this challenge; and where he refers to old misconceptions, such as the infamous "climate and civilisation" hypothesis of Huntington, he fails to put them in proper perspective.

Hans von Storch is at the Institute of Hydrophysics, GKSS Research Center, PO Box, 21502 Geesthacht, Germany.

\section{Thumbs up for signal work}

\section{The Expression of the Emotions in Man and Animals}

by Charles Darwin

Third edition, with introduction, afterword and commentaries by Paul Ekman. HarperCollins/Oxford University Press: 1998. Pp. 473. £16.99, \$30

\section{Simon Baron-Cohen}

Almost everyone has heard of Darwin's The Origin of Species, and many will have heard of his book The Descent of Man. These books disseminated the theory that now stands as the framework for the biological sciences. But his book The Expression of the Emotions in Man and Animals is less well known, except possibly among readers in the field of psychology. This book is where Darwin laid out his highly original thesis that emotional expressions in humans have their counterparts in the behaviour of other species, suggesting an evolved commonality of form and function.

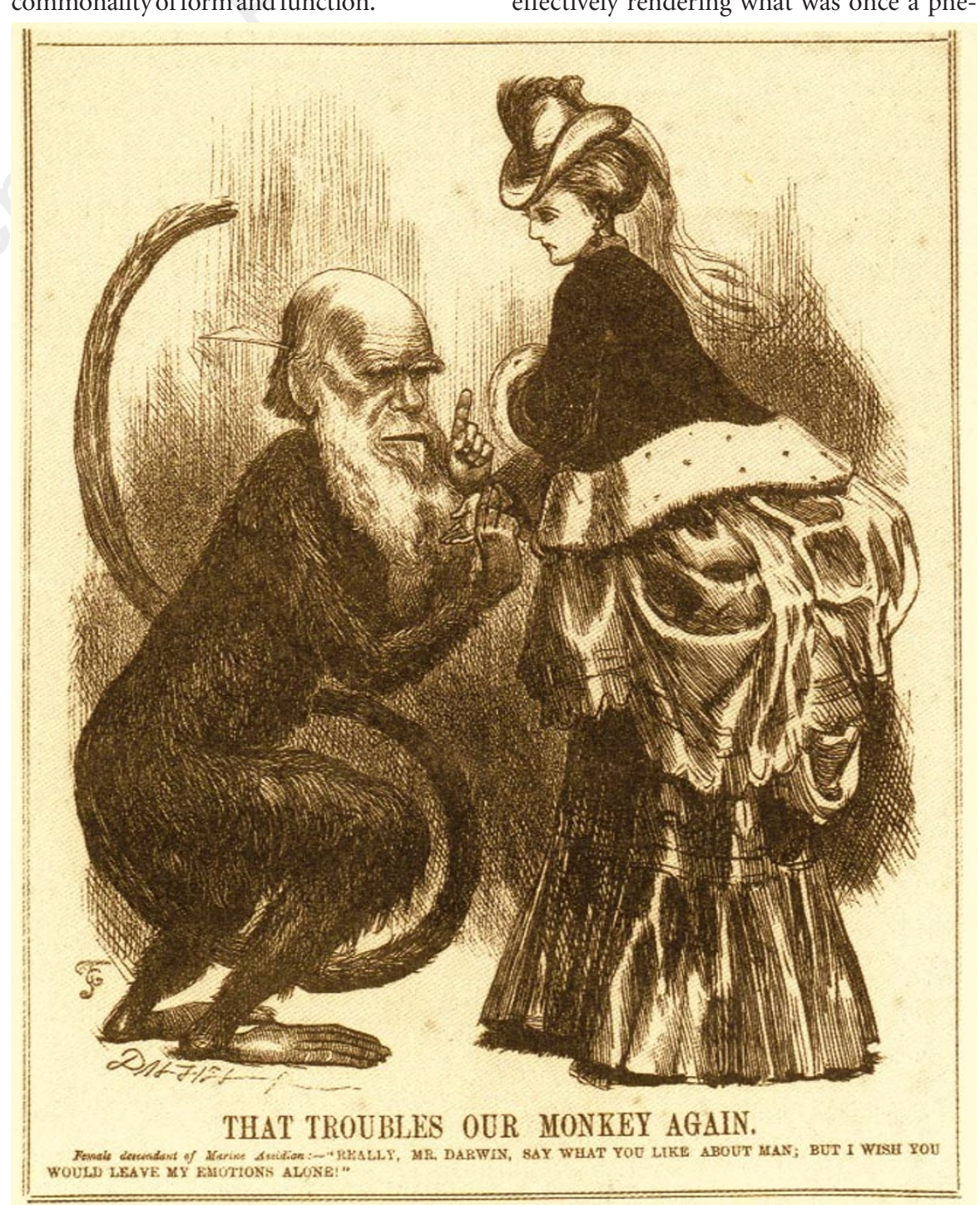

Seconding that emotion: she may not have liked it, but Ekman's findings back up Darwin's work.

The first edition came out in 1872 and sold 9,000 copies in the first four months. The text contains a wealth of detail from a wide range of primate species, describing the expression of fear, anger, contentment and sadness. It relates these to observations of the behaviour of human infants. Some of the observations were drawn directly from his descriptions of his own child: for example, where he details the expression of guilt on his son's face when the boy was just two years old.

The second edition of the book was edited by Darwin's son Francis, and appeared in 1889 , seven years after Charles Darwin died. Francis appears to have brought it out because Charles had prepared many revisions and additional material not available in the first edition.

Now, more than a century later, the world's leading Darwin scholar on the subject of the emotions, Paul Ekman, has produced a treasure trove of a third edition. Ekman is widely known in this field for his empirical contribution to defining the musculature of facial expressions of emotion, effectively rendering what was once a phe- 